Advances in Gene Technology: The Genome and Beyond -

Structural Biology for Medicine (Proceedings of the 2002 Miami

Nature Biotechnology Winter Symposium)

TheScientificWorld 2002, 2(S2), 51-52

ISSN 1532-2246; DOI 10.1100/tsw.2002.26

\title{
ENGINEERING MONOMERIC GLYCOGENIN
}

David Dwek, David Fisher, Joseph Lomako, Weislawa M. Lomako, and William J. Whelan Department of Biochemistry and Molecular Biology, University of Miami School of Medicine, P.O. Box 016129 (M823), Miami, FL 33101

INTRODUCTION. Glycogenin is an autocatalytic, self-glucosylating muscle protein that is the primer for glycogen synthesis. It has $\mathrm{Mr} 37 \mathrm{kDa}$ and constructs a maltosaccharide chain on its Tyr 194, the chain in turn being elongated by glycogen synthase. UDPglucose is the substrate for both enzymes[1]. There is an obvious interest in the two-dimensional structure of glycogenin, but attempts by a colleague to crystallize the enzyme have proven unsuccessful. We observed that recombinant glycogenin contained oligomers, apparently formed via disulfide bonds between various of its four cysteine residues. The glycogenin did not contain free sulfhydryl groups, suggesting that all the cysteines were involved in intra- or intermolecular disulfide bonds. Splitting of the intermolecular bonds by thiol reagents only took place when the protein was heated. Accordingly, to obtain monomeric glycogenin we have constructed a series of mutants in which the cysteines were replaced by serine.

MATERIALS AND METHODS. Wild-type rabbit muscle glycogenin was expressed and mutagenized as by Alonso et al.[2]. Activity measurements and Western blotting were carried out as by Lomako et al.[3].

RESULTS AND DISCUSSION. Glycogenin has Cys residues at positions 88, 97, 130, and 270[4]. All possible single, double, triple, and quadruple mutations were constructed and expressed. The extracts were tested for (1) activity by self-glucosylation with UDP $\left[{ }^{14} \mathrm{C}\right]$ glucose, (2) level of expression, by Western blotting, and (3) whether oligomers were noted, by SDSPAGE, directly, and by radioautography, after $\left[{ }^{14} \mathrm{C}\right]$-glucosylation.

The levels of activity and expression in the extracts are recorded qualitatively in Table 1, relative to what was seen with wild-type glycogenin, expressed under the same conditions.

A wide range of activities and levels of expression was seen, ranging from no expression, through poor expression and activity to levels comparable with those of wild-type enzyme. It is noteworthy that while all the single Cys mutants still formed oligomers, none of the double, triple or quadruple mutants did so, save that no expression of the $88+97+130$ mutant was seen.

Several of the multiple mutants are candidates for crystallization of their glycogenins, when oligomerization, if that is a factor in inhibiting crystallization, will not interfere.

\section{TABLE 1}


Mutation of Cysteine Residues to Serine in Recombinant Rabbit-Muscle Glycogenin Position of Mutation

$$
\text { Activity Expression Oligomerization }
$$

Single Mutants

$\begin{array}{llll}88 & ++ & ++ & \text { Yes } \\ 97 & ++++ & +++++ & \text { Yes } \\ 130 & ++ & +++ & \text { Yes } \\ 270 & +++++ & +++ & \text { Yes } \\ & & & \\ \text { Double mutants } & & & \\ 88+97 & +++ & +++ & \text { No } \\ 88+130 & \text { No } & + & \text { No } \\ 88+270 & ++++ & +++ & \text { No } \\ 97+130 & ++ & +++ & \text { No } \\ 97+270 & ++++ & ++++ & \text { No } \\ 130+270 & \text { No } & ++ & \text { No }\end{array}$

Triple mutants

$\begin{array}{llll}88+97+130 & \text { No } & \text { No } & \text { No } \\ 88+97+270 & ++ & ++ & \text { No } \\ 88+130+270 & ++ & +++ & \text { No } \\ 97+130+270 & \text { No } & + & \text { No }\end{array}$

Quadruple mutants

$88+97+130+270 \quad$ No $\quad++\quad$ No

The results are presented relative to wild-type glycogenin, which was assigned 6+.

Supported by a grant from NIH, DK 37500 .

\section{REFERENCES}

1. $\quad$ Alonso, M.D. Lomako, J., Lomako, W.M., and Whelan, W.J. (1995) FASEB J. 9, 1126-1127.

2. $\quad$ Alonso, M.D., Lomako, J., Lomako, W.M., and Whelan, W.J. (1994) FEBS Lett. 342, 38-42.

3. Lomako, J., Lomako, W.M., and Whelan, W.J. (1988) FASEB J. 2, 3097-3103.

4. Viscupic, E., Cao, Y., Zahng, W., Chag, C., DePaoli-Roach, A.A., and Roach, P.J. (1992) J. Biol. Chem. 267, 25759-25763. 

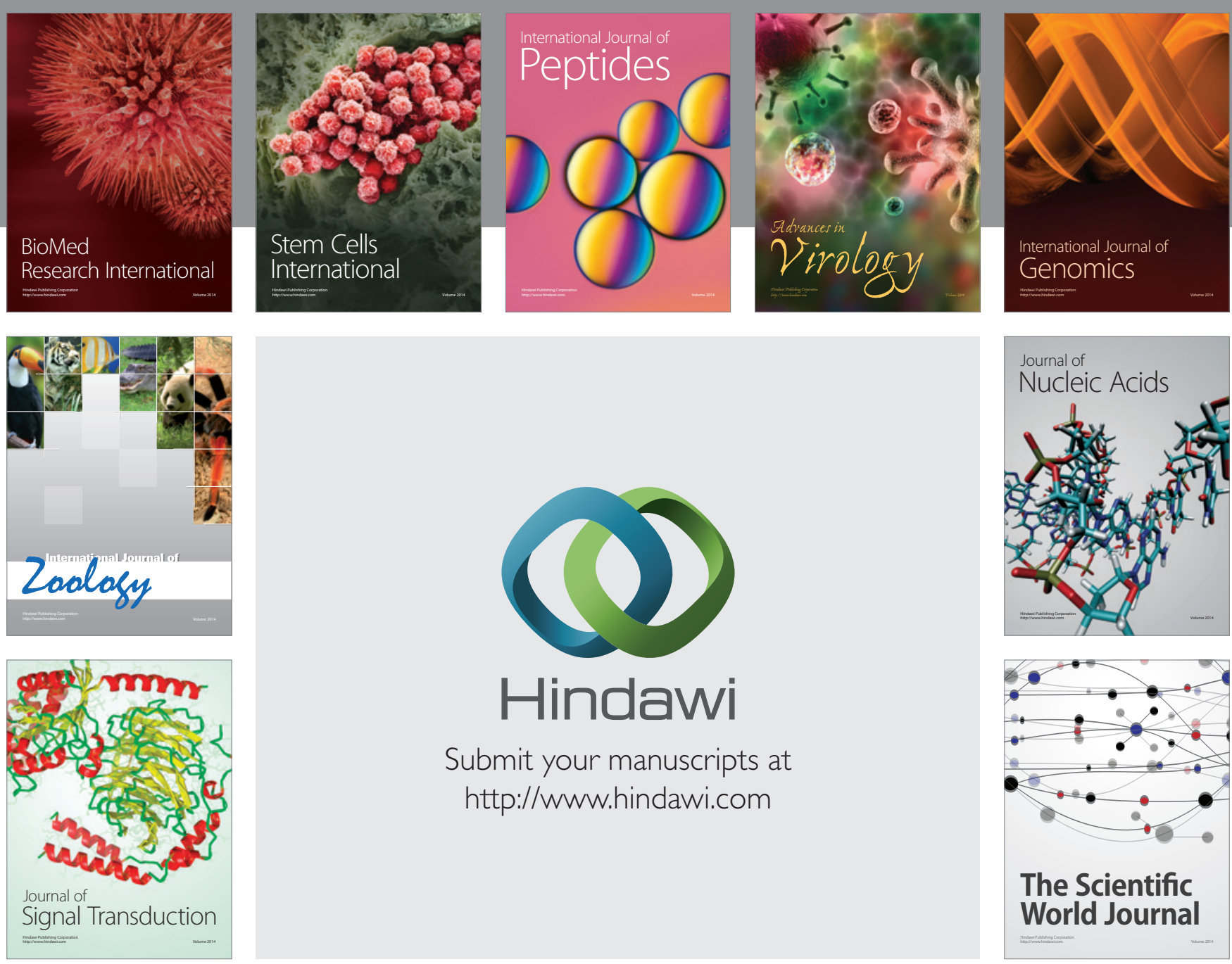

Submit your manuscripts at

http://www.hindawi.com
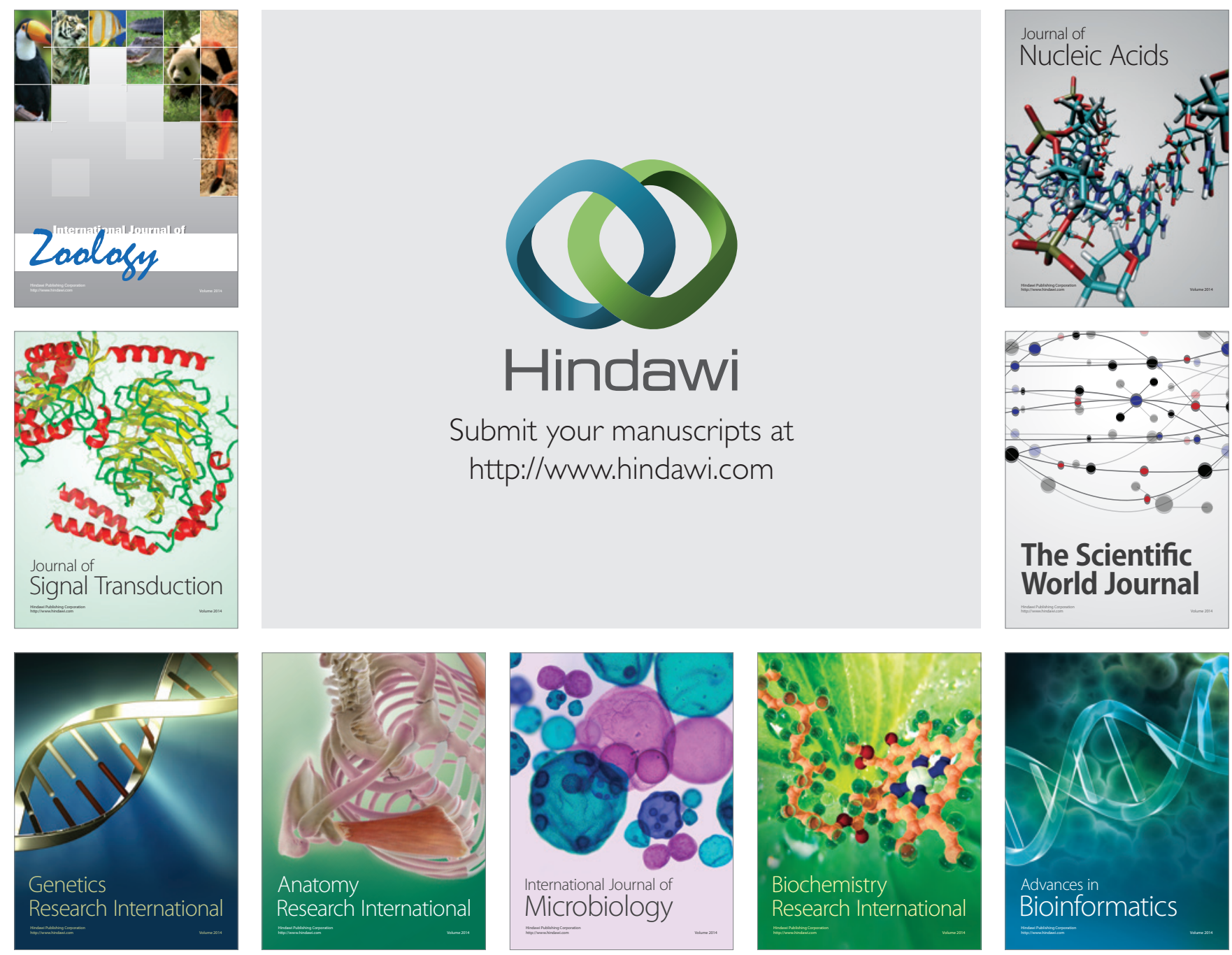

The Scientific World Journal
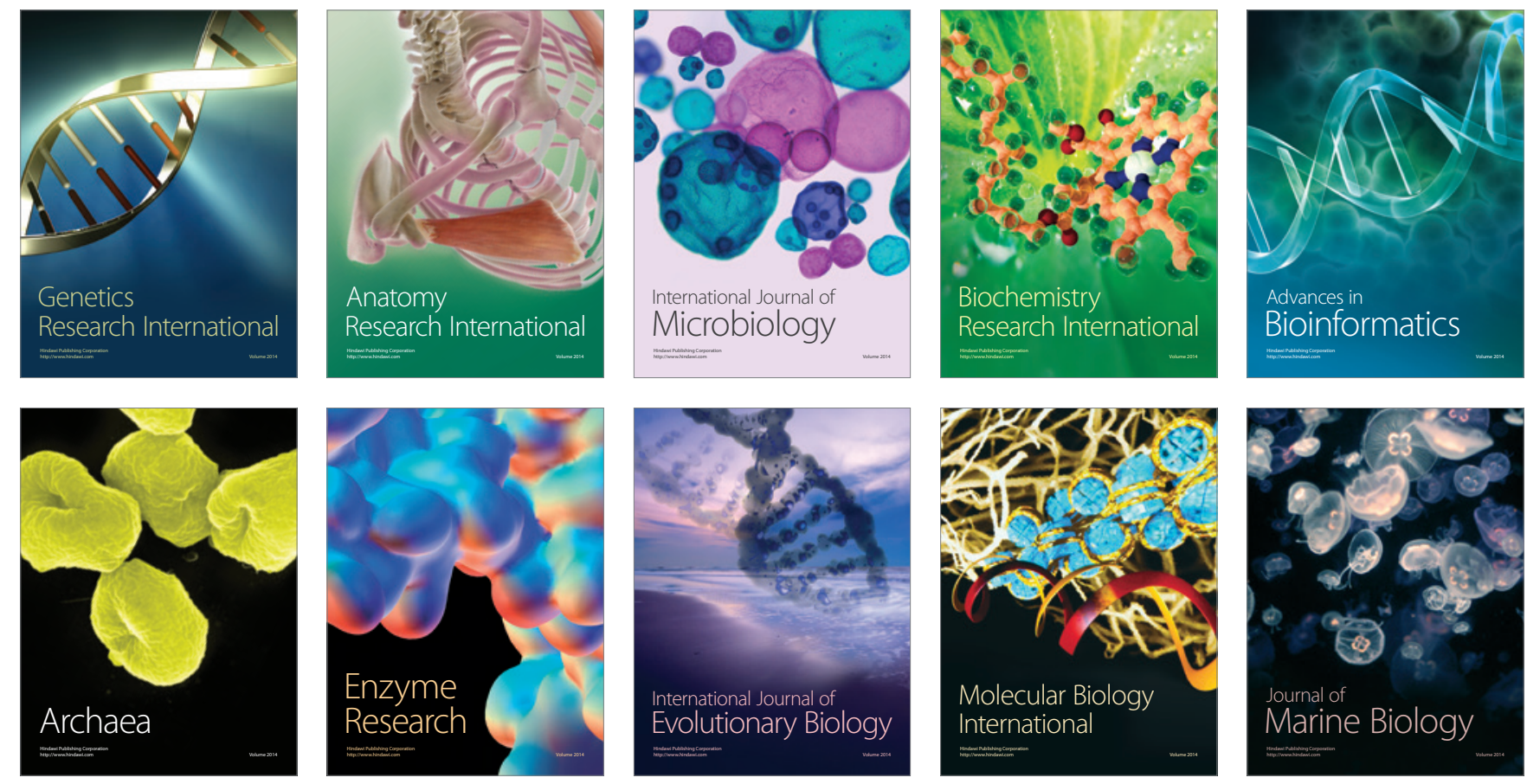